\title{
Flow-dependent effect of formoterol dry-powder inhaled from the Aerolizer $\circledast$
}

\author{
K.G. Nielsen, M. Skov, B. Klug, M. Ifversen, H. Bisgaard
}

Flow-dependent effect of formoterol dry-powder inhaled from the Aerolizer( ${ }^{\circledR}$. K.G. Nielsen, M. Skov, B. Klug, M. Ifversen, H. Bisgaard. CERS Journals Ltd 1997.

ABSTRACT: The output and size distribution of aerosols from dry powder inhalers are dependent on the flow rate through the device. Therefore, in an in vivo study, we examined the flow-dependency of the effect of formoterol when delivered from a dry powder inhaler, the Aerolizer ${ }^{\circledR}$, in a flow range relevant to schoolchildren.

In a preliminary study comprising 126 asthmatic children aged 3-10 yrs, the relationship between age and peak inspiratory flow (PIF) rate through the Aerolizer ${ }^{\circledR}$ was determined. Mean PIF was $104 \mathrm{~L} \cdot \mathrm{min}^{-1}$ and all children aged $>5$ yrs performed a PIF $>60 \mathrm{~L} \cdot \mathrm{min}^{-1}$. Sixteen children aged 8-15 yrs with exercise-induced asthma (EIA) took part in the main trial comparing the protective effect of $12 \mu \mathrm{g}$ formoterol inhaled at 60 and $120 \mathrm{~L} \cdot \mathrm{min}^{-1}$. The effect from high and low inspiratory flow was judged from the protective effect against EIA $12 \mathrm{~h}$ after drug administration.

The decrease in forced expiratory volume in one second (FEV1) after exercise was $34 \%$ on the placebo day, but only $15 \%$ when formoterol was inhaled at the high flow rate. This difference was statistically significant. The decrease in FEV1 was $23 \%$ after treatment with formoterol inhaled at the low flow rate, that was not significantly different from placebo or from high-flow formoterol treatment. These clinical findings correspond with the in vitro findings of flow-dependent fine particle mass from the Aerolizer ${ }^{\circledR}$, and corroborate the relationship between fine particle mass of aerosol and clinical effect.

The results indicate a flow-dependent effect of formoterol dry powder inhaled from the Aerolizer ${ }^{\circledR}$, within the range of inspiratory flow rate obtainable by schoolchildren. This questions its applicability in children with asthma. Eur Respir J 1997; 10: 2105-2109.
Dept of Paediatrics, National University Hospital, Copenhagen, Denmark.

Correspondence: H. Bisgaard

Dept of Paediatrics

National University Hospital

DK-2100 Copenhagen

Denmark

Keywords: Dry powder inhaler exercise-induced asthma

formoterol

inhalation flow

Received: November 211996

Accepted after revision May 101997
Formoterol is a highly potent, selective $\beta_{2}$-agonist producing bronchodilatation of rapid onset [1] and long duration [2-5]. Inhalation of formoterol $(12 \mu \mathrm{g})$, both from pressurized aerosol and from dry powder, has been shown to provide children with clinically significant protection against methacholine induced bronchoconstriction [4] and exercise-induced asthma (EIA) $[6,7]$ for at least $12 \mathrm{~h}$.

The major advantage of dry powder inhalers (DPIs) is the avoidance of propellants and lubricants, and the fact that they are actuated when the child is inhaling through the device $[8,9]$, thereby overcoming the problem of co-ordination. Formoterol dry powder is delivered from a single-dose dry powder capsule inhaler, the Aerolizer® [10], previously known as the ISF device (ITALSEBER Farmaceutici Italy). The powder comprises micronized active substance and lactose, which serves as a bulking agent. The major disadvantage of DPIs is that the size distribution of the aerosol is dependent on the flow rate through the device, which depends on the internal resistance of the device and the effort of the child. Such effort dependency varies between the DPIs available [11].

The objective of this trial was to perform an in vivo study of flow-dependency of the effect of formoterol when delivered from the Aerolizer® in a flow range relevant to schoolchildren. The flow-dependency was judged indirectly from the protective effect against EIA $12 \mathrm{~h}$ after inhalation of formoterol at two different flow rates: 60 and $120 \mathrm{~L} \cdot \mathrm{min}^{-1}$.

\section{Materials and methods}

The Aerolizer ${ }^{\circledR}$ is a DPI operated by placing a capsule containing the medication in the capsule chamber in the base of the device. Two buttons on each side of the capsule chamber are then depressed, which results in the piercing of each end of the capsule by a set of four pins. On inhalation by the patient, the capsule is lifted out of the capsule chamber, into the inhalation chamber where it rotates, releasing powder into the airstream. A coarse grid in the mouthpiece serves to allow only powder to escape from the device. The specific airflow resistance of the Aerolizer ${ }^{\circledR}$ is $0.055 \mathrm{cmH}_{2} \mathrm{O}$ 1/2. $\mathrm{L}^{-1} \cdot \mathrm{min}^{-1}[12]$.

The study was performed in two parts. In a preliminary study, the relationship between age and peak inspiratory flow (PIF) rate through the Aerolizer@ was assessed. The results were then used in the main study of flow-dependency. 


\section{Preliminary study: age and PIF relationship}

One hundred and twenty six asthmatic, asymptomatic children, aged 3-10 yrs, were instructed to inhale through the empty device connected to a pneumotachograph run from a Master Screen unit (E. Jäeger \& Co., Würzburg, Germany). The highest PIF following three attempts was read from the flow-volume curve.

\section{Main study: investigation of flow-dependency}

Sixteen children, 12 boys and 4 girls aged 8-15 yrs (mean $12 \mathrm{yrs}$ ), with bronchial asthma as defined in the International Consensus Report on the Diagnosis and Treatment of Asthma [13] were included. All children were treated with a $\beta_{2}$-agonist on an as-needed basis, and all except two were treated with inhaled steroids, budesonide or beclomethasone dipropionate in doses ranging 400-1,200 $\mu \mathrm{g} \cdot \mathrm{day}^{-1}$. All patients had been clinically stable for at least 1 month prior to the start of the trial, and the dosage of inhaled corticosteroids was constant 1 month prior to and throughout the study period. On all examination days, the following periods of abstinence from bronchodilating drugs were adhered to: longacting $\beta_{2}$-agonist $48 \mathrm{~h}$; and inhaled short-acting $\beta_{2}$-agonist $6 \mathrm{~h}$. None of the patients used any other antiasthma drugs.

The exercise challenge consisted of 6 min of continuous treadmill running, with a constant workload adjusted to induce a cardiac frequency of approximately 180 beats $\min ^{-1}$ measured by radiotelemetry. The inclination of the treadmill was $10 \%$. The children wore a noseclip during exercise. The relative humidity and room temperature were registered. In case of severe EIA the patient was allowed to use short-acting $\beta_{2}$-agonist.

On inclusion day (day 1), forced expiratory volume in one second (FEV1) ranged 60-109\% of predicted normal value for height [14], and the median percentage decrease in FEV1 after exercise test was $27 \%$ (17-70\%). On each of the following study days (days 2-5) the baseline FEV1 value was within $\pm 15 \%$ of the value recorded prior to exercise on the inclusion day. Intervals between study days were at least 2 days and not more than 49 days, although the majority $(90 \%)$ of intervals were no longer than 30 days.

\section{Design}

The trial was of a double-blind, placebo-controlled, cross-over design. On examination days $2-5$, the treatment sequences (the order of formoterol and placebo administration) and inspiratory flow rate sequences (the order of low and high inhalation rates) were allocated at random using a Latin-Greek square design. To secure the blinding in this trial design, two placebo days were necessary.

All treatments were administered between 08.00 and 09.00 h. Prior to the inhalation of the study medication, the vital capacity was measured. An empty Aerolizer ${ }^{\circledR}$ device and an Aerolizer ${ }^{\circledR}$ device loaded with dry powder study medication (formoterol or placebo) were placed in parallel connected by a valve system, which enabled an instantaneous shift of the airflow from the empty device to the device containing study medication. The connection between the device containing the trial medication and the mouth of the child had no bends, and was $10 \mathrm{~mL}$ in volume. The devices were in serial connection with a pneumotachograph run from the Master Screen unit (E. Jäeger \& Co., Würzburg, Germany).

Initially, the patient inhaled through the empty device and was trained to reach the desired inspiratory flow rate. The inspiratory flow was visualized simultaneously on a computer screen. When the patient was fully trained, the valve was activated, switching the airflow from the empty device to the Aerolizer ${ }^{\circledR}$ containing the study medication. The switch was computer controlled via the pneumotachograph and occurred when $250 \mathrm{~mL}$ of air had been inhaled, assuring instantaneous activation of the dry powder by the target flow, i.e. avoiding any initial slow rise in flow, which would be deleterious to optimal dispersion of the dry powder [15].

The inspiratory flow rate during inhalation of the study medication was calculated from the hard copy screen printout of the flow-volume curve as the average inspiratory flow rate during inhalation of the first $500 \mathrm{~mL}$ through the Aerolizer ${ }^{\circledR}$ containing the study medication. It was intended that the flow rate should be within $\pm 25 \%$ of the target flow rate. In addition, at least $75 \%$ of the vital capacity should be inhaled during the manoeuvre. After completing the inhalation, the patient held his/her breath, so that the overall inhalation procedure took $10 \mathrm{~s}$. After the patient had inhaled the study medication, the device was opened to inspect whether the capsule had been emptied.

Two exercise tests were performed on each of the examination days (days 2-5), $3 \mathrm{~h}$ and $12 \mathrm{~h}$ after inhalation of the study medication.

FEV1 was measured by a dry spirometer (Vitalograph Ltd, Buckingham, UK) as the best of three forced expiratory manoeuvres just before administration of study medication, $1,2,3,4,6,8$ and $12 \mathrm{~h}$ after study medication, and 1, 3, 5, 10, 15 and $30 \mathrm{~min}$ after the end of each exercise test. Cardiac frequency and blood pressure measurements were performed at all of the timepoints mentioned above, with the exceptions of 3 and 10 min after each exercise test. At each study day, all patients were staying at the out-patient clinic and supervised by the investigators for $12.5 \mathrm{~h}$.

The trial was performed in accordance with the latest amendment of the Declaration of Helsinki, approved by the Local Ethics Committee (KF 02054/93), and conducted according to the guidelines for Good Clinical Practice. All children and their parents gave written informed consent.

\section{Statistical analysis}

The main outcome measure was the bronchial response to exercise $12 \mathrm{~h}$ after treatment administration in terms of maximum percentage decrease in lung function (FEV1) from the value immediately before exercise (Ex):

$\%$ decrease $=($ preEx - lowest postEx $) /$ preEx $\times 100$

The Wilcoxon-Pratt test for matched pairs was used to compare the maximum percentage decrease in FEV1 
after different treatments. The central tendency was depicted by the median value.

An exploratory analysis of FEV1 at every time-point was also performed. Log-transformation of FEV1 was performed to secure normal distribution and analysed by ordinary least squares, taking treatment, patient, period and log-baseline value into account. Analysis of covariance (ANCOVA) was carried out using the following model:

$\log (\mathrm{x})=$ patient + period+treatment+log (baseline value)

where $\mathrm{x}$ is the value of FEV1 at a particular time-point. The contrasts of treatment differences were tested. Both intention-to-treat population and secondary population (those patients who did not take rescue medication and who completed the whole observation period of $12.5 \mathrm{~h}$ after trial medication) were analysed. A p-value of less than 0.05 was considered significant.

\section{Results}

Age and PIF relationship in children using the Aerolizer ${ }^{\circledR}$

The PIF rates of the 126 children are presented in figure 1 . The mean achievable PIF through the Aerolizer® was $104 \mathrm{~L} \cdot \mathrm{min}^{-1}$. All children aged $\geq 5 \mathrm{yrs}$, except one, performed a PIF of $\geq 60 \mathrm{~L} \cdot \mathrm{min}^{-1}$, and children aged 8 yrs performed a mean PIF of $120 \mathrm{~L} \cdot \mathrm{min}^{-1}$. Therefore, 60 and $120 \mathrm{~L} \cdot \mathrm{min}^{-1}$ were chosen for the subsequent main trial.

\section{Main study: investigation of flow-dependency}

The mean flow rate $( \pm \mathrm{SD})$ on the days when inhalation of formoterol was aimed at $60 \mathrm{~L} \cdot \mathrm{min}^{-1}$ (form LOw $_{\text {) }}$ ) and on the days when it was aimed at $120 \mathrm{~L} \cdot \mathrm{min}^{-1}$ $\left(\right.$ form $_{\mathrm{HIGH}}$ ) were $64 \pm 9.5$ and $125 \pm 16.8 \mathrm{~L} \cdot \mathrm{min}^{-1}$, respectively. In no case was dry powder left in the capsule after inhalation.

Two of the 16 patients were not able to inhale within the desired high flow rate range on one occasion each:

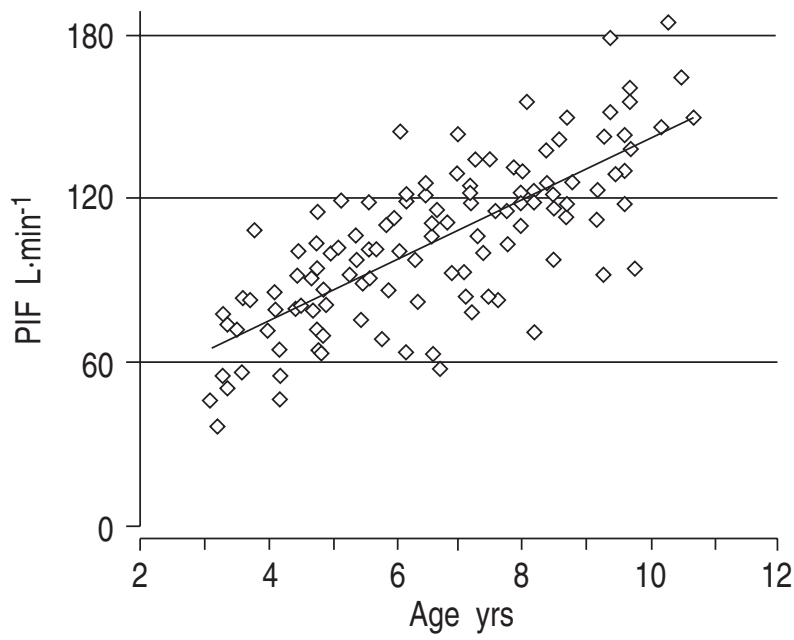

Fig. 1. - Relationship between peak inspiratory flow (PIF) through the Aerolizer ${ }^{\circledR}$ and age in 126 asymptomatic, asthmatic children aged 3-10 yrs. one inhaled formoterol at a rate of $82 \mathrm{~L} \cdot \mathrm{min}^{-1}$ and another inhaled placebo at a rate of $86 \mathrm{~L} \cdot \mathrm{min}^{-1}$; however, they both emptied the capsules. One patient inhaled formoterol at a rate of $93 \mathrm{~L} \cdot \mathrm{min}^{-1}$ when he was scheduled to inhale at low flow. According to the intention-to-treat principle, the data from these three patients were included in the analyses.

The maximum percentage decrease in FEV1 after the exercise tests 3 and $12 \mathrm{~h}$ after inhalation of study medication are illustrated in figure $2 \mathrm{a}$ and $\mathrm{b}$, respectively. Results after placebo are presented as mean values from low and high inhalation flow, respectively. Three hours after dosing, the maximum percentage decrease in FEV1 following exercise challenge was without significant difference between formoterol inhaled at 60 and 120 $\mathrm{L} \cdot \mathrm{min}^{-1}$, whereas both formoterol treatments were significantly superior to placebo (fig. 2a). Twelve hours (fig. 2b) after placebo, the median maximum percentage decrease in FEV1 (range) was 34 (11-55) \%; after form $_{\text {Low }}, 23(0-58) \%$ (low flow vs placebo: $\left.\mathrm{p}=0.14\right)$; and after form ${ }_{\text {HIGH }}, 15$ (2-67) \% (high flow vs placebo:

a)
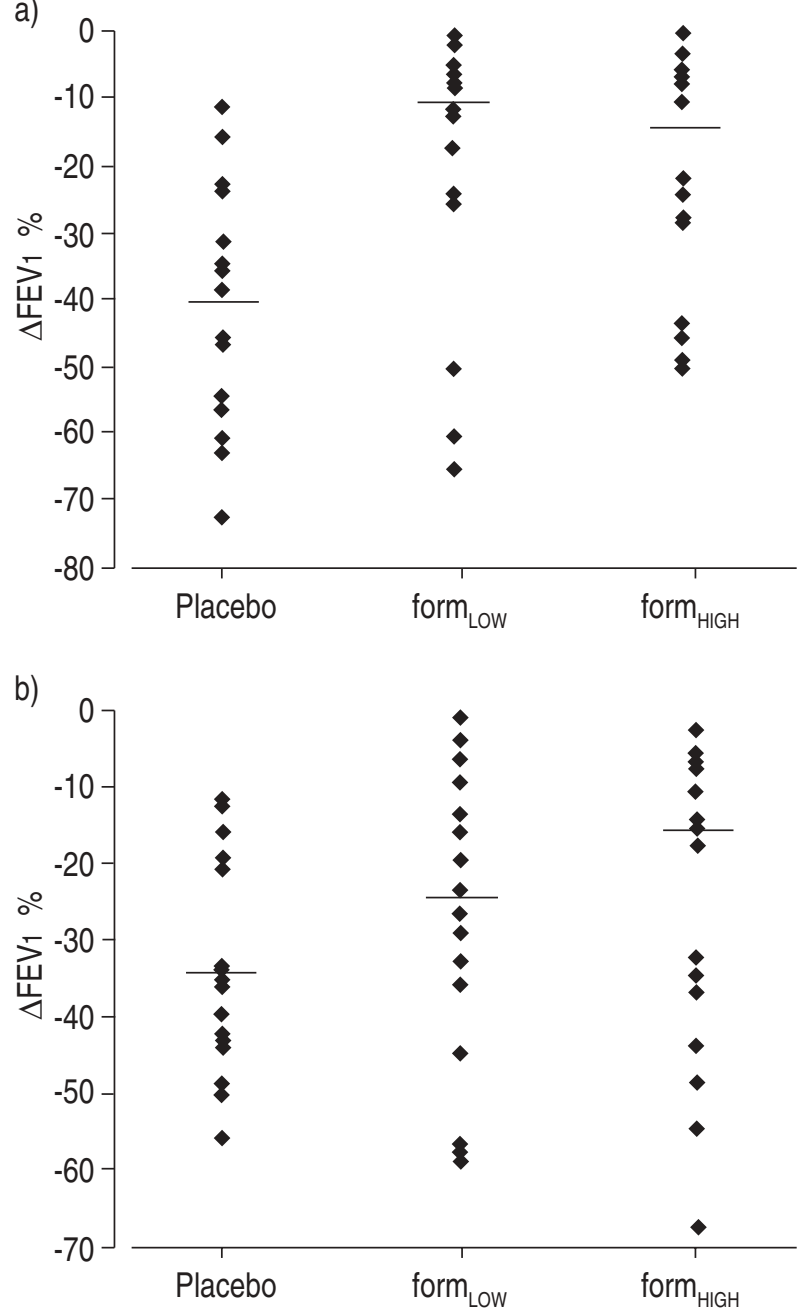

Fig. 2. - Maximum percentage decrease in forced expiratory volume in one second $\left(\triangle F E V_{1}\right)$ after exercise in 16 children: a) $3 \mathrm{~h}$; and b) $12 \mathrm{~h}$ after inhalation of placebo, formoterol inhaled at low flow rate $\left(\right.$ form $\left._{\text {LOw }}\right)$ and formoterol inhaled at high flow rate (form ${ }_{\mathrm{HIGH}}$ ). Medians are indicated by horizontal lines. 
$\mathrm{p}<0.05)$. The difference between form $\mathrm{HIGH}_{\mathrm{H}}$ and form $\mathrm{LOW}_{\mathrm{L}}$ was not statistically significant.

Seven of the 16 patients experienced a drop in FEV1 of more than $30 \%$ at the $12 \mathrm{~h}$ exercise test after form $\mathrm{HIGH}_{\text {. }}$ Four of these were consistently very poorly protected throughout the study. The remaining three patients were significantly better protected at the $3 \mathrm{~h}$ exercise test. Seven patients used rescue medication after the first and/or second exercise challenge on the investigators discretion on one or more occasions on study days 2-5. Rescue medication was used by six patients after the first exercise test when treated with placebo. Two of these also used rescue when treated with formoterol inhaled at low flow, and two also when treated with formoterol inhaled at high flow rate. Five of the seven patients also used rescue after the exercise test at $12 \mathrm{~h}$ postinhalation: four used rescue after placebo; two used rescue after form LOW $_{\text {and }}$ form $_{\mathrm{HIGH}}$; and one used rescue after form ${ }_{\mathrm{HIGH}}$.

The exploratory analysis of FEV1 at every time-point for the intention-to-treat population showed no difference at any time-point between form LOW $_{\text {or form }}$ HIGH When comparing form $\mathrm{HIGH}_{\mathrm{H}}$ and placebo, formoterol was statistically significantly superior to placebo at all timepoints. A similar comparison of form $\mathrm{LOw}_{\text {and }}$ andacebo showed that formoterol was superior at the first exercise challenge at $3 \mathrm{~h}$ and up to and including the $4 \mathrm{~h}$ time-point, but after that point there was no longer a consistent significant difference. These results were mirrored when analysing the secondary population, i.e. those patients who did not take rescue medication and who completed the whole observation period of $12.5 \mathrm{~h}$ after trial medication. The time course of FEV1 for the secondary population is shown in figure 3 .

Headache occurred in one patient during placebo treatment. No other adverse events occurred and no particular patterns concerning pulse rate and blood pressure were observed.

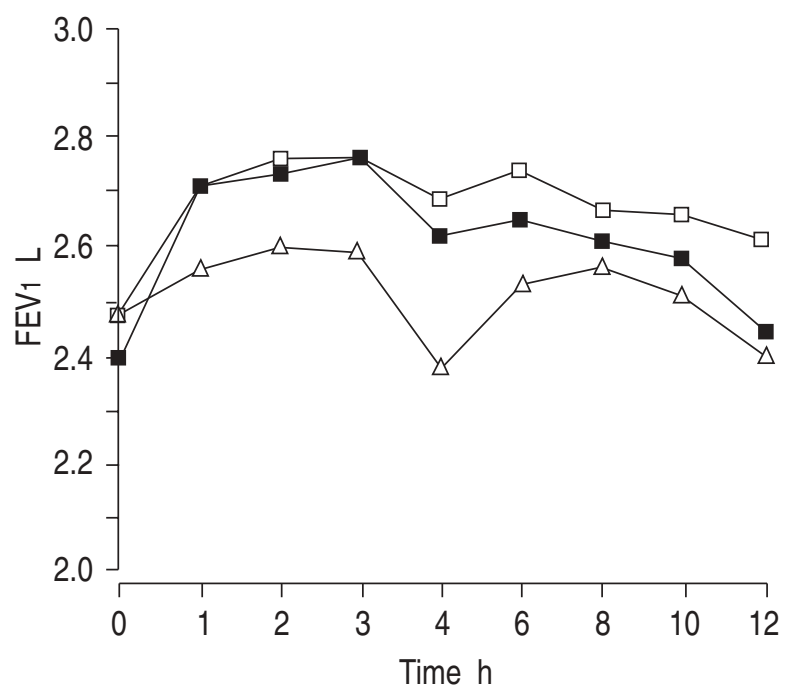

Fig. 3. - Time course of mean forced expiratory volume in one second (FEV1) values for treatment for the secondary population, i.e. omitting the patients who took rescue medication after the exercise test at $3 \mathrm{~h}$. Immediate postexercise values are not shown. form $_{\mathrm{LOW}}$, i.e. formoterol inhaled at $60 \mathrm{~L} \cdot \mathrm{min}^{-1} ; \square \square-$ form $_{\mathrm{HIGH}}$, i.e. formoterol inhaled at $120 \mathrm{~L} \cdot \mathrm{min}^{-1} ;-\Delta-$ : placebo.

\section{Discussion}

From our previous study, we know that $12 \mu \mathrm{g}$ of formoterol dry powder inhaled by a vigorous inhalation through the Aerolizer ${ }^{\circledR}$ affords good protection against EIA $12 \mathrm{~h}$ postinhalation [7]. The present study was designed to reveal any flow-dependency of the formoterol DPI within the flow range obtainable by schoolchildren. The flow range for this particular device was outlined in the preliminary study, and we found a significant linear age-related PIF performance through the device in the age interval 3-10 yrs, ranging 35-184 $\mathrm{L} \cdot \mathrm{min}^{-1}$ with a mean of $104 \mathrm{~L} \cdot \mathrm{min}^{-1}$. These flows were determined as the best of three attempts, which is likely to overestimate the actual flow performance in clinical practice. In 6 yr old children the lower -2 SD flow rate was $54 \mathrm{~L} \cdot \mathrm{min}^{-1}$.

In the subsequent study of the effect of formoterol inhaled from the Aerolizer ${ }^{\circledR}$, we showed that effect is dependent on the inspiratory flow rate performed through the Aerolizer ${ }^{\circledR}$, within the PIF range $60-120 \mathrm{~L} \cdot \mathrm{min}^{-1}$, which is the flow rate relevant to schoolchildren. The bronchodilating effect from form LOw $_{\text {was }}$ not significantly different from the placebo effect from $5 \mathrm{~h}$ postinhalation. In contrast, the effect of form $\mathrm{HIGH}_{\mathrm{H}}$ was significant for at least $12 \mathrm{~h}$. The effect of form ${ }_{\text {HIGH }}$ and form ${ }_{\text {LOW }}$ did not differ significantly, although obviously a type 2 error cannot be excluded.

Such a reduced clinical effect of formoterol at $12 \mathrm{~h}$ postinhalation indicates a suboptimal dispersion of the dry-powder when inhaled at a low flow rate. This is in agreement with in vitro measurements showing a reduced fraction of fine particles when the Aerolizer ${ }^{\circledR}$ is activated by $40 \mathrm{~L} \cdot \mathrm{min}^{-1}$ as compared to $80 \mathrm{~L} \cdot \mathrm{min}^{-1}$; the mass median aerodynamic diameter (MMAD) of the aerosol from the Aerolizer® at the chosen flow rates was markedly different (7.2 and $5.3 \mu \mathrm{m}$, respectively) [10]. This correlation between in vitro measurements of fine particle mass and clinical outcome attests to the usefulness of in vitro particle measurements for evaluation of clinical outcome.

Our findings are in contrast to the same study [10] investigating the influence of two different inspiratory flow rates through the Aerolizer ${ }^{\circledR}$ on the time-course of bronchodilatation afforded by salbutamol dry powder $(400 \mu \mathrm{g})$ in 16 asthmatic adults. The investigators found no differences between the time-courses of FEV1 when salbutamol was inhaled at flows as low as 40 and 80 $\mathrm{L} \cdot \mathrm{min}^{-1}$ despite differences in MMAD in the in vitro part of the study. However, a dose of $400 \mu \mathrm{g}$ salbutamol is at the plateau of the dose-response relationship, questioning the sensitivity of such a study to reveal any flowdependency in vivo. In addition these patients were not challenged with a bronchoconstrictor stimulus, which reduces the sensitivity to detect differences in treatment effects. Finally, the flow rates tested in this adult group of patients tend to be below the flow rates relevant to children. By adding a bronchoconstrictor challenge at the end of the expected time-course of action, the flowdependency of the Aerolizer ${ }^{\circledR}$ was revealed. The $12 \mathrm{~h}$ time-point was chosen as the end-point, because any difference in effect is most likely to be revealed when the effect is marginal.

The set-up was developed to enable studies of the influence of maximal flow on the clinical effect. A prolonged 
time to reach maximal flow reduces the efficiency of the aerosolizing property of DPIs [15]. This rise time varies considerably from one child to another, and could have confounded the present evaluation of flow-dependency. We therefore shunted the initial rising flow outside the device, to ensure that the scheduled inspiratory flow was studied under optimal conditions. This procedure ensures that the flow under study rises as a stepfunction and, therefore, affords optimal circumstances to the device. Without this precaution, the performance of the Aerolizer® would be expected to be less efficient. In our previous study [7], the inhalation procedure was more vigorous and without shunting of the rising part of the flow performance. Despite the difference in inhalation procedures, the effect against EIA with respect to form ${ }_{\mathrm{HIGH}}$ was comparable and not significantly different at the $12 \mathrm{~h}$ time-point in the two studies.

The results indicate that the highest possible inspiratory flow rate should be recommended for inhalation of formoterol dry powder capsules through the Aerolizer®. The actual flow performances measured indicate that such high flow rates may not be consistently achievable by schoolchildren.

The Aerolizer ${ }^{\circledR}$ is a single-dose, dry powder capsule inhaler. From our clinical experience, at times: the capsule fails to rotate in the inhalation chamber despite vigorous inhalation; the needles get stuck in the capsule, the capsule gets stuck in the capsule chamber during inhalation; and the capsule is inadequately pierced or completely crushed by the needles, all of which lead to imperfect release of the medication. Other investigators have also reported on occasional malfunctioning of the ISF device [16]. It is, therefore, important that patients always check to see if the capsule is empty, and if not inhale again to empty completely.

In conclusion, the results of this trial indicate a flowdependent effect of formoterol dry powder inhaled from the Aerolizer $\AA$, within the range of inspiratory flow rate obtainable in schoolchildren, which questions its applicability in children.

Acknowledgements: The authors thank Ciba-Geigy for help with statistical analyses and the GCP-monitoring. Ciba-Geigy is also thanked for initiating and supporting the study.

\section{References}

1. Wegener T, Hedenström H, Melander B. Rapid onset of action of inhaled formoterol in asthmatic patients. Chest 1992; 102: 535-538.
2. Ramsdale EH, Otis J, Kline PA, Gontovnick LS, Hargreave FE, O'Byrne PM. Prolonged protection against methacholine-induced bronchoconstriction by the inhaled $\beta$ agonist formoterol. Am Rev Respir Dis 1991; 143: 98-101.

3. Maesen FPV, Smeets JJ, Gubbelmans HLL, Zweers PGMA. Bronchodilator effect of inhaled formoterol vs salbutamol over 12 hours. Chest 1990; 97: 590-594.

4. Becker AB, Simons FER, MacMillan JL, Faridy T. Formoterol, a new long-acting selective $\beta_{2}$-adrenergic receptor agonist: double-blind comparison with salbutamol and placebo in children with asthma. J Allergy Clin Immunol 1989; 84: 891-895.

5. Graff-Lonnevig V, Browaldh L. Twelve hours bronchodilating effect of inhaled formoterol in children with asthma: a double-blind cross-over study versus salbutamol. Clin Exp Allergy 1990; 20: 429-432.

6. Boner AL, Spezia E, Piovesan P, Chiocca E, Maiocchi $\mathrm{G}$. Inhaled formoterol in the prevention of exerciseinduced bronchoconstriction in asthmatic children. $\mathrm{Am}$ J Respir Crit Care Med 1994; 149: 935-939.

7. Daugbjerg P, Nielsen KG, Skov M, Bisgaard H. Duration of action of formoterol and salbutamol dry powder inhalation in prevention of exercise-induced asthma in children. Acta Paediatr 1996; 85: 684-687.

8. Bisgaard H. Aerosol treatment of young children. Eur Respir Rev 1994; 4: 15-20.

9. Crompton GK. Dry powder inhalers: advantages and limitations. J Aerosol Med 1991; 4 (3): 151-156.

10. Zanen P, van Spiegel PI, van der Kolk H, Tushuizen E, Enthoven R. The effect of the inhalation flow on the performance of a dry powder inhalation system. Int $J$ Pharmaceut 1992; 81: 199-203.

11. Olsson B, Asking L. Critical aspects of the function of inspiratory flow driven inhalers. J Aerosol Med 1994; (Suppl. 1): 43-47.

12. Clark AR, Hollingworth AM. The relationship between powder inhaler resistance and peak inspiratory conditions in healthy volunteers implication for in vitro testing. J Aerosol Med 1993; 2: 99-110.

13. International Consensus Report on Diagnosis and Treatment of Asthma. Eur Respir J 1992; 5: 601-641.

14. Polgar G, Promadhat V. In: Pulmonary Function Testing in Children: Techniques and Standards. London, W.B. Saunders, 1971.

15. Bisgaard H, Klug B, Burnell PKP, Sumby RS. Use of inhalation profiles from paediatric asthmatics using the diskus and turbuhaler inhalers to evaluate product performance in vitro. Am J Respir Crit Care Med 1996; 153: A75.

16. Steffensen I Faurschou P, Riska H, Rostrup J, Wegener T. Inhaled formoterol dry powder in the treatment of patients with reversible obstructive airway disease. Allergy 1995; 50: 657-663. 